\title{
EVALUATION OF CBR USING GEOSYNTHETICS IN SOIL LAYERS
}

\author{
M Rama Krishna', B Naga Malleswara Rao ${ }^{2}$ \\ ${ }^{1} M$-Tech student, civil engineering Department, VNR VJIET, Telangana, India \\ ${ }^{2}$ Head of the civil department, Civil engineering, VNR VJIET, Telangana, India
}

\begin{abstract}
In urban areas, the service life of pavement on weaker soil subgrade affected severely due to their high compressibility and plasticity behaviour. These soils possess less strength, CBR value and have high affinity to moisture content. Also the seasonal changes affects the soil properties adversely. Stabilization techniques using geo-synthetic materials for improving properties of these types of soft subgrades. To increase the sub grade soil strength and to reduce the thickness of flexible pavement, Geosynthetics are increasingly used in wide variety of civil engineering applications. Geo-synthetics are the cost-effective ground modification materials which acts as a reinforcement and also increases the stability and bearing capacity of soil. Many researchers recommends the use of geo-synthetic material performs good results in soil stabilization. From this view, Evaluation has been made on poorly graded sand with the inclusion of go-grid, geo-textile and geo-composite materials between soil layers in different proportions. The CBR and shear parameters are determined for different combinations of subgrade thickness. The geo-engineering properties such as Atterberg limits, grain size distribution, compaction characteristics, and CBR value of poorly graded sand were evaluated and reported. To get the maximum California bearing ratio (CBR), the present study is put forward to understand the strength change in the soil with the addition of geo-synthetic materials. Such a study would be helpful in material selection based on site condition and strength gain along with economy.
\end{abstract}

Keywords: Geo-synthetics, CBR, Strength, Economy.

\section{INTRODUCTION}

Soil is typically a non-homogeneous, porous, earthen material whose engineering behavior is influenced by changes on moisture content and density. Based on the origin, soil can be broadly classified as organic and inorganic. Organic soils are mixture derived from growth and decay of plant life and also accumulation of skeleton or shell of small organism. Inorganic soils are derived from the mechanical or chemical weathering of rocks. Inorganic soil that is still located at the place where it was formed is referred to residual soil. If the soil has been moved to another location by gravity, water or wind, it is referred to as transported soil.

Sandy soil has the biggest particles and the size of particles does determine the degree of aeration and drainage that the soil allows. It consists of rock and mineral particles are very small. Sandy soil is formed by the disintegration and weathering of rocks such as lime stone, granite, quartz and shale. Sandy soil is gritty to the touch and will often be dry. Soils with high sand content break apart easily and will not form a clump when squeezed hard. Wet sand does not stick together. Sand particles are visible to the high and will not merge with other grains. Hence the sub-grade of pavement and its characteristics to be modified using a suitable stabilization technique. Stabilization involves the methods used for modifying the properties of a soil to improve its engineering performance. In the construction of road and airfield prevents the main objective of stabilization is to increase the strength or stability of soil and to reduce the construction cost by making best use of the locally available materials.

\section{MATERIALS USED}

Soils those are highly susceptible to Volume and strength changes can cause severe roughness and accelerate the deterioration of the pavement structure in the form of increased cracking and decreased ride quality when combined with truck traffic. Generally, the stiffness (in terms of resilient modulus) of some soils is highly dependent on moisture and stress state. In some cases, the sub-grade soil can be treated with various materials to improve the strength and stiffness characteristics of the soil. Stabilization of soils is usually performed for three reasons:

1. As a construction platform to dry very wet soils and facilitate compaction of the upper layers-for this case, the stabilized soil is usually not considered as a structural layer in the pavement design process.

2. To strengthen a weak soil and restrict the Volume change potential of a highly plastic or compressible soil-for this case, the modified soil is usually given some structural value or credit in the pavement design process.

3. To reduce moisture susceptibility of fine grain soils.

Mechanical stabilization using thick gravel layers or granular layers in conjunction with geotextiles, geo-grid, geo-composites an effective technique for improving roadway support over soft, wet sub-grades. Thick granular layers provide a working platform, but do not provide strengthening of the sub-grade. In fact, construction of thick granular layers in some cases results in disturbance of the sub-grade due to required construction activities. Thick 
granular layers are also used to avoid or reduce frost problems by providing a protection to the underlying subgrade layers.
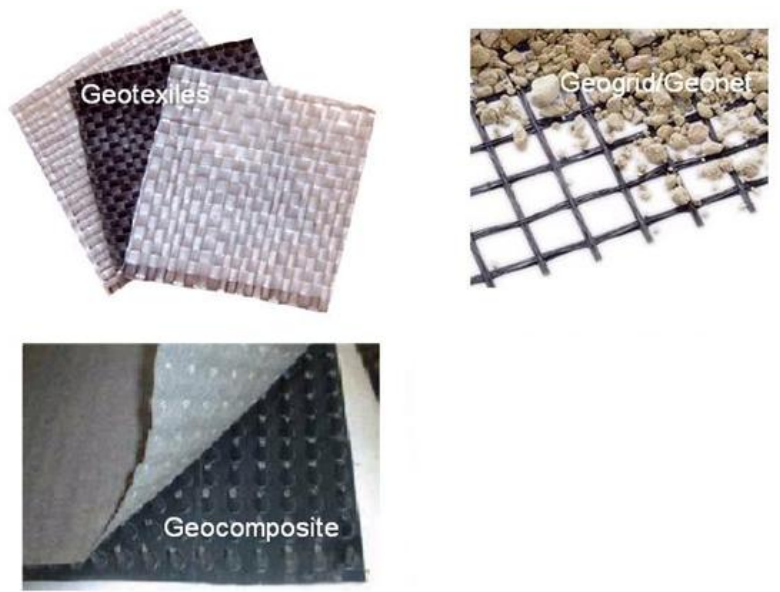

Fig-1: different types of Geo-synthetics

\section{OBJECTIVES OF THE STUDY}

- $\quad$ To determine the maximum CBR for poorly graded sandy soil by placing geo-synthetic material in layers.

- $\quad$ To check the layer thickness in subgrade for poorly graded sandy soil by placing geo-synthetic materials.

- To establish a method and to evaluate the strength of soil.

- Improving the strength of soil by addition of Geosynthetic material such as geo textile, Geo composite and geo grid at different soil layers

\section{SCOPE OF THE PROJECT}

- We can come to know the maximum CBR value, when the geo-synthetic material placed in different soil layers

- The change in the values of CBR with the inclusion of reinforcement material (Geo-synthetics), between soil layers would be brought out from the present study.

- Such a study would be useful in selecting the geosynthetic material for improving the soil subgrade.

\section{METHODOLOGY}

For the present study, the various tests performed along with a brief description of the procedure have been included in the following. The tests include the index tests for soil classification, the engineering tests to understand the behavior of the soils. These tests were performed on materials namely locally available sand.

\subsection{Laboratory Tests}

- Sieve analysis

- Standard proctor test

- Atterberg Limits

- Specific gravity

- Direct shear

- $\quad$ CBR (California bearing ratio)
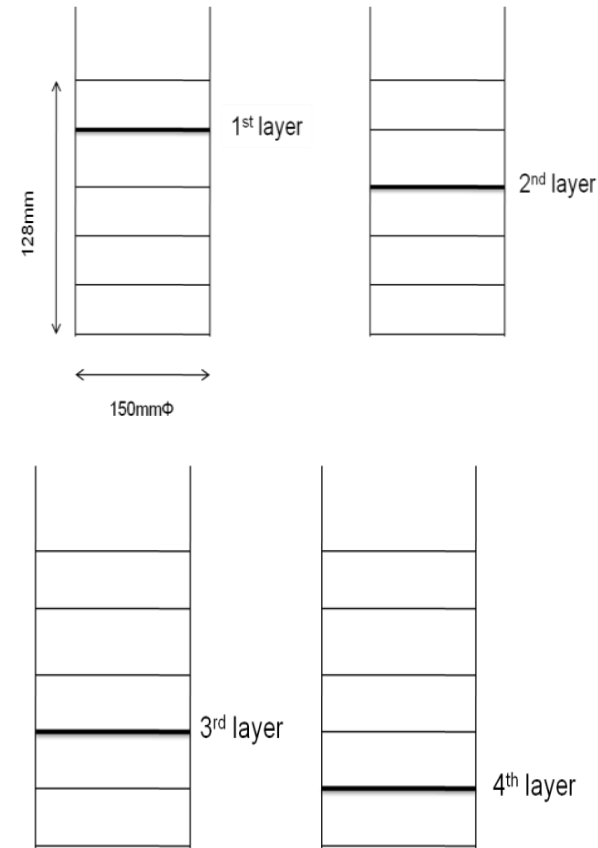

Fig-2: Geo-synthetics placement in layers

\section{RESULTS AND DISCUSSIONS}

The results of various tests performed on clay are discussed in this section. With the aim to understand the changes in the CBR values of the soil with the introduction of geosynthetic material, the CBR test has been conducted on the soil and with different geosynthetics placed at different layers. The soil in the CBR mould has been divided into 5 layers with equal weights (considering constant density and Volume per layer) and the various geosynthetic material viz., geotextile, GT, geogrid, GG, geocomposite, GC (geotextile and geogrid) has been placed accordingly to understand the best possible location of the geosynthetic material to yield maximum CBR value. Also, as the part of this study the crushed tyre material in the ratios of $2 \%, 5 \%$ and $10 \%$ has been mixed thoroughly with soil and the CBR tests have been performed for each combination. The results obtained in all the tests have been analyzed and the discussion has been included here in.

\subsection{Material Properties}

Table 1: Properties of SANDY soil

\begin{tabular}{|l|l|l|}
\hline Property & Symbols & Sandy soil \\
\hline Specific Gravity & $\mathrm{G}$ & 2.63 \\
\hline $\begin{array}{l}\text { Coefficient } \\
\text { curvature }\left(\mathrm{C}_{\mathrm{c}}\right) \\
\text { coefficient } \\
\text { uniformity }\left(\mathrm{C}_{\mathrm{u}}\right)\end{array}$ & of & 3.19 \\
\hline Sand $(\%)$ & & 11 \\
\hline Silt $(\%)$ & & 85 \\
\hline Clay $(\%)$ & & 15 \\
\hline Liquid Limit & LL & 0 \\
\hline Plastic Limit & PL & 31.25 \\
\hline $\begin{array}{l}\left.\text { Cohesion(kg/cm }{ }^{2}\right) \\
\text { of internal friction }\end{array}$ & & -- \\
\hline
\end{tabular}




\begin{tabular}{|l|l|l|} 
& & $\begin{array}{l}\text { Poorly } \\
\text { graded } \\
\text { sand }\end{array}$ \\
\hline Classification & SP & 10.93 \\
\hline OMC (\%) & & 1.97 \\
\hline MDD (g/cc) & & 10.03 \\
\hline CBR (\%) & & \\
\hline
\end{tabular}

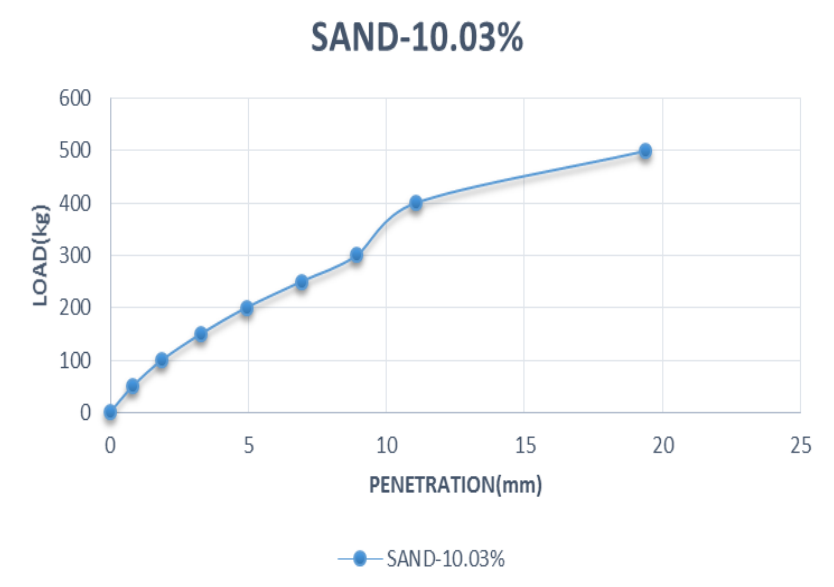

Graph 1 shows Load penetration curve from CBR test on SANDY soil

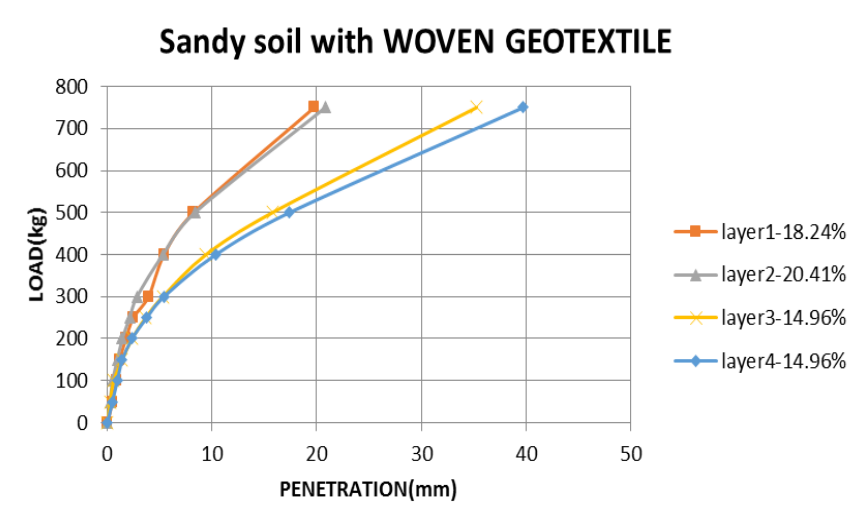

Graph 2: Load penetration curve from CBR test on SANDY soil with the inclusion of GTW

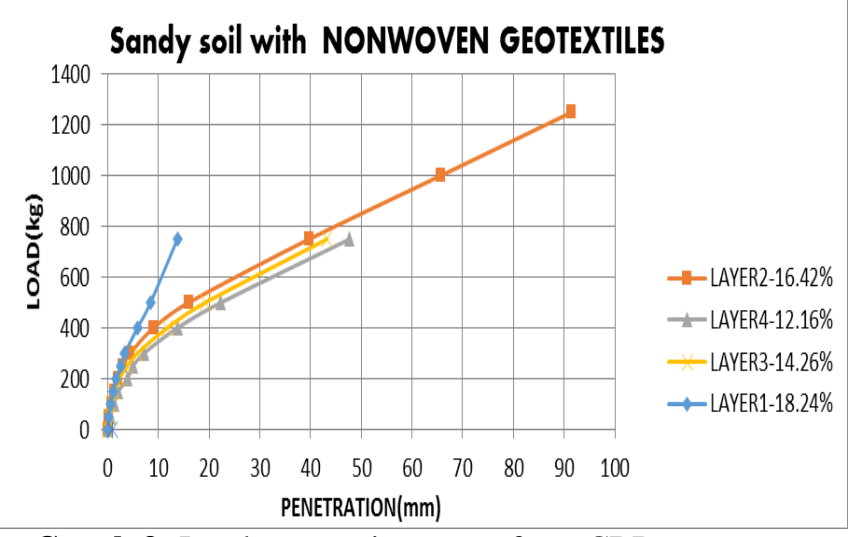

Graph 3: Load penetration curve from CBR test on SANDY soil with inclusion of GTNW

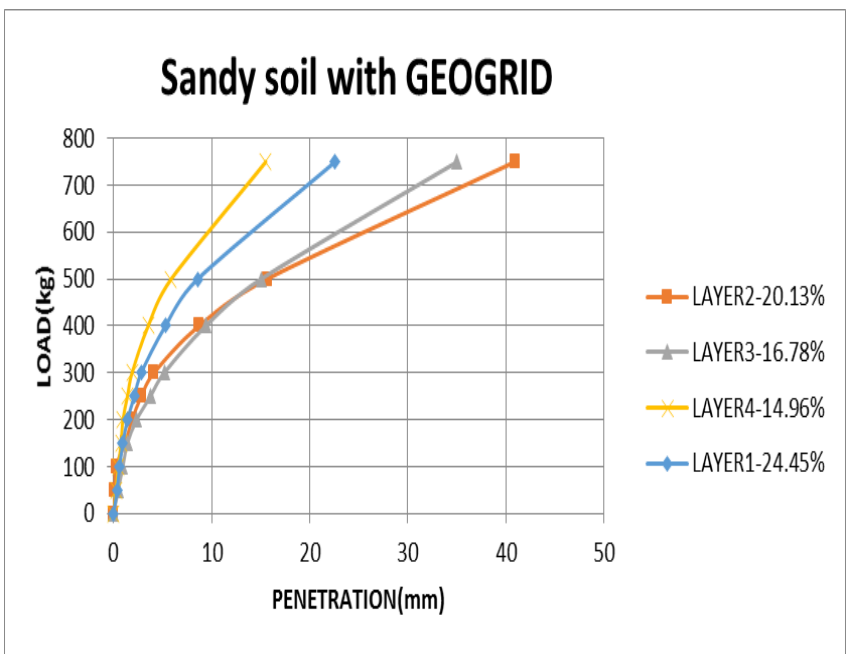

Graph 4: Load penetration curve from CBR test on SANDY soil with inclusion of GG

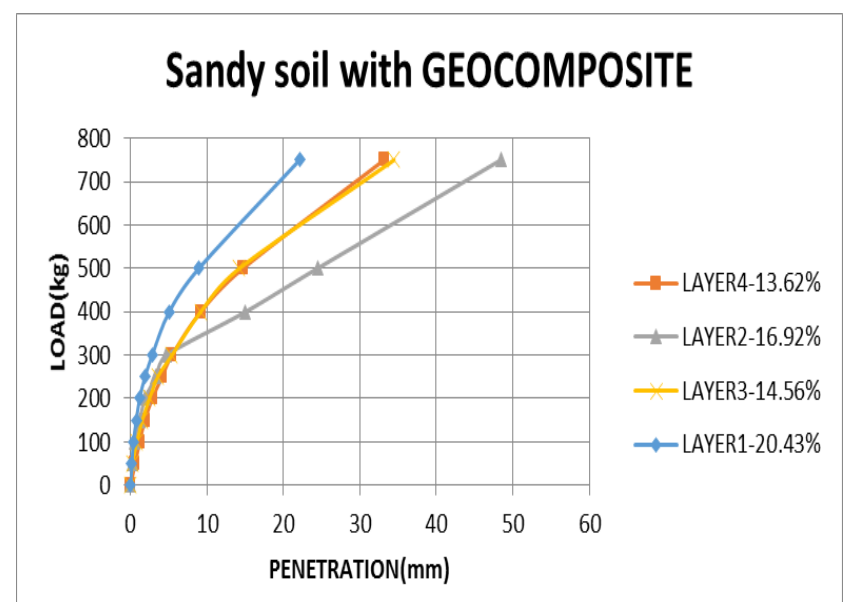

Graph 5: Load penetration curve from CBR test on SAND with inclusion of GC

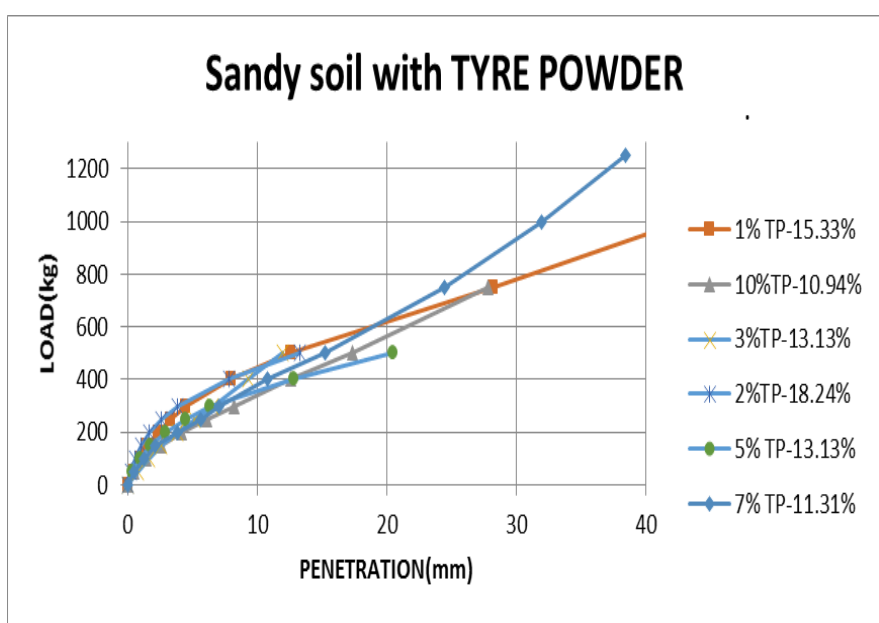

Graph 6: Load penetration curve from CBR test on SANDY soil with TP

Table 2: Maximum values of CBR with addition of GTW,

GTNW, GG, GC and TP
\begin{tabular}{|l|l|}
\hline Material & CBR \\
\hline GTW & $20.41 \%$ \\
\hline
\end{tabular}




\begin{tabular}{|l|l|}
\hline GTNW & $18.24 \%$ \\
\hline GG & $24.45 \%$ \\
\hline GC & $20.43 \%$ \\
\hline TP & $18.25 \%$ \\
\hline
\end{tabular}

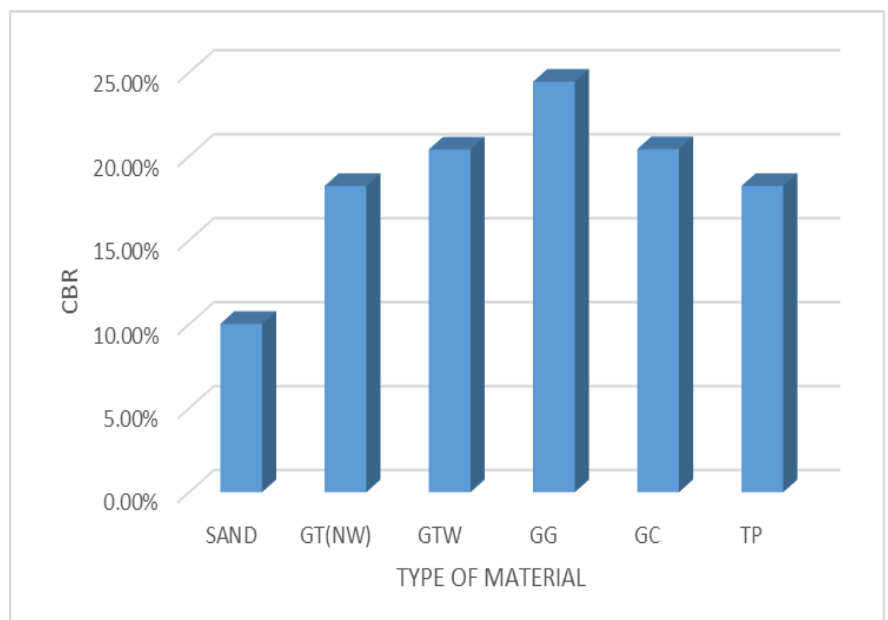

Graph 7: Maximum values of CBR using GTNW, GTW, GG, GC, and TP on SANDY soil

\begin{tabular}{|l|l|}
\hline Material & CBR \\
\hline GTW & $103.45 \%$ \\
\hline GTNW & $81.15 \%$ \\
\hline GG & $143.76 \%$ \\
\hline GC & $103.68 \%$ \\
\hline TP & $81.85 \%$ \\
\hline
\end{tabular}

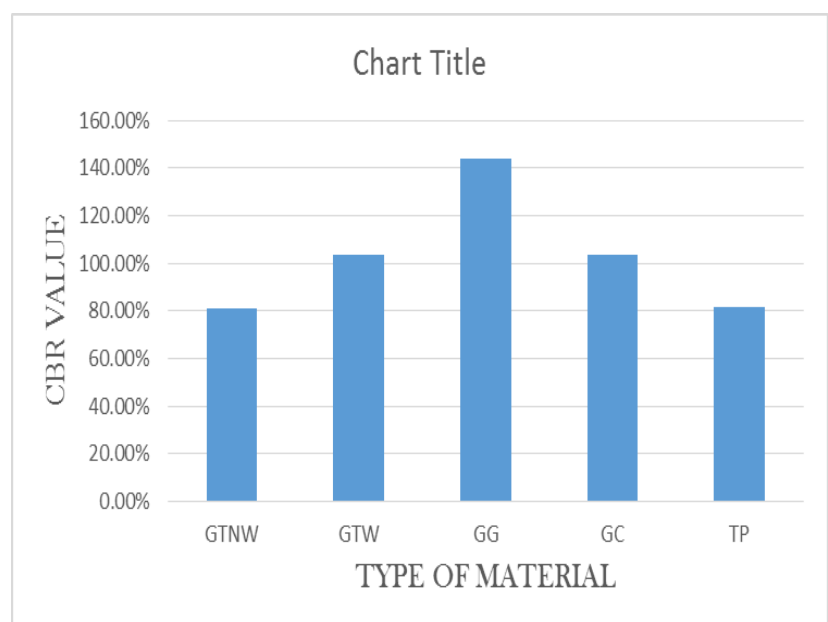

Graph 8: Maximum \% increase in values of CBR using GTNW, GTW, GG, GC, and TP on SANDY soil

\section{CONCLUSION}

From the project work, we got to know that we have limited quantity of good quality of earth soil is available. It is not possible to provide good quality soil for every construction, in such circumstances we need to go for the modification methods. An attempt has been made to use the waste materials such as TP to modify the properties of the soil which is available in bulk quantity with inclusion of GTW, GG, GC, GTNW and TP. The disposal of these materials are utilizing several acres of land which can be used for agriculture, buildings, transportation, commercial complexes etc.,

- With inclusion of geosynthetics (such as GTW, GTNW, GG, and GC) in layers within the geomaterials, it proved that GG gives more CBR values in SANDY soil.

- With inclusion of GTW in layers within the soil sample such as layer 1, layer 2, layer 3, layer 4 from the study it shows that GTW at layer 2 in SANDY soil gives $103.4 \%$ more CBR value.

- With inclusion of GTNW in layers within soil sample from the study it shows that GTNW at layer 1 in SANDY soil gives $81.15 \%$ more CBR value.

- With inclusion of GG in layers within the soil sample from the study it shows that GG at layer 1 in SANDY soil gives $143 \%$ more CBR value.

- With inclusion of GC in layers within the soil sample from the study it shows that GC at layer 1 in SANDY soil gives $103.6 \%$ more CBR value.

- Using TP at 1\%, 2\%, 3\% shows that TP in SANDY soil at $2 \%$ gives $81.8 \%$ more CBR value.

\section{ACKNOWLEDGEMENTS}

Firstly I would like to express my immense gratitude and heartfelt thanks towards our institution VNR Vignana Jyothi Institute of Engineering \&Technology, which created a great platform to attain profound technical skills in the field of Civil Engineering, thereby fulfilling my most cherished goal.

I extended my heartfelt thanks to my guide Dr. B Naga Malleswara Rao for the guidance and support. Also, thanks to Sri K. Suresh, who has taught and helped me in the process of experimentation throughout M.Tech project.

\section{REFERENCES}

[1] Bonaparte, Holtz and Giroud, "Soil Reinforcement Design Using Geotextiles and Geogrids", American Society for testing and Materials, ASTM, Vol. 952, pp. 69-116, 1987.

[2] Cetin, H., M. Fener, and O. Gunaydin, "Geotechnical properties of tire-cohesive clayey soil mixtures as a fill material”, Engineering Geology, Vol. 88 (1-2), pp. 110-120, 2006.

[3] Chandra, S., Viladkar, M.N and Nagrale, "Mechanistic approach for fiber-reinforced flexible pavements", Journal of Transportation Engineering, Vol.134 (1), pp. 15-23, 2008.

[4] Charan, H.D, "Probabilistic analysis of randomly distributed fiber-reinforced soil", Ph. D.Thesis Dept. of Civil Engineering, IIT Roorkee, 1995.

[5] Consoli, N.C., Montardo, J.P., Prietto, P.D.M and Pasa, "Engineering behavior of sand reinforced with plastic waste",Journal of Geotechnical and GeoenvironmentalEngg ASCE,Vol. 128 (6), pp. 462472, 2002. 
[6] H.P Singh, "Improvement in CBR value of soil reinforced with jute geotextile layers", International Journal of Environmental Science and Engineering, Vol. (05), pp. 1438-1442, 2012

[7] Mandeep and Anupam, "A review on the soil stabilization with waste materials", International Journal of Engineering Research and Applications (IJERA), pp. 11-16, 2014.

\section{BIOGRAPHIES}

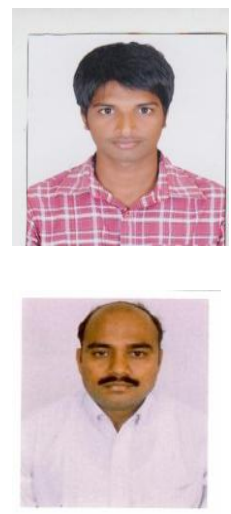

M RAMA KRISHNA pursuing m-tech (geotechnical engineering) in VNR VJIET, bachupally under the guidance of Dr. B N M RAO.

Dr. B N M RAO head of the civil engineering department in VNR VJIET, bachupally. 